\title{
Difusão em Arquivos e o centro de \\ memória - Unicamp
}

Ananda Mendes Lima

DOI: 10.11606/issn.2318-8855.v10i2p274-295

Resumo: Considerando a difusão um dos componentes basilares das instituições de arquivo, este artigo tem como objetivo observar a importância desse segmento com relação a divulgação do conhecimento, partindo das iniciativas do Centro de Memória - Unicamp (CMU). Dessa forma, pretende-se apresentar algumas noções teóricas relativas à difusão e seu papel no arquivo, com o objetivo de situar as propostas do CMU, seguida da introdução do centro e sua trajetória e, por fim, as atividades em desenvolvimento e planejadas para os próximos períodos. A fins de conclusão, serão expostas reflexões acerca da importância da difusão em arquivos, e o comprometimento com a divulgação científica de qualidade tanto para o público acadêmico quanto à comunidade.

Palavras-chave: Arquivo, centro de memória, difusão, divulgação científica 


\section{artigos}

\section{Difusão em Arquivos e o centro de memória - Unicamp}

\section{Introdução}

Os arquivos são entidades inseridas dentro das demandas das épocas em que atuam, acompanhando também a trajetória dos significados e ressignificações dos documentos. Em seus primórdios modernos, no século XIX, com a construção dos Estados e identidade nacional e a busca por meios que legitimassem sua formação e soberania, os arquivos atuam como agentes que abrigam e possibilitam o acesso aos bens, que agem como prova e testemunho histórico das nações (LE GOFF, 1984, p. 9596 apud COSTA, 1998, p. 191). Com a passagem do tempo e as mudanças nas perspectivas sobre as esferas pública e privada, associadas aos novos usos da documentação pela ciência histórica, o acesso à informação passa a ser considerado um direito civil, quadro que se fortalece com o avançar do século XX.

A trajetória da arquivística, apesar de suas especificidades, está intimamente ligada ao trabalho do historiador e as novas tendências historiográficas, que passam a ver o documento de arquivo para além de prova, como fonte para diversas análises tanto do seu conteúdo quanto do que diz sobre o seu contexto de produção e suas informações implícitas. Dessa forma, é imprescindível ao historiador o conhecimento das funções e métodos arquivísticos, para que possa realizar de forma satisfatória suas investigações, levando em conta a subjetividade dos processos pelos quais passam os objetos de estudo até serem disponibilizados ao pesquisador.

O século XX consolida uma mudança que está em curso desde fins do século XVIII, com a Revolução Francesa e, em especial, a partir do fim da Segunda Guerra Mundial e da Declaração dos Direitos Humanos, de 1948 (COSTA, 1998, p. 192), que defende, entre outras coisas, o direito à informação. Essa mudança faz com que a esfera de atuação do arquivo e do arquivista se estenda para além da academia e do Estado até a comunidade, ampliando seu público. Para tanto, a área de difusão ganha destaque, uma vez que tem como objetivo tornar acessível a documentação custodiada Epígrafe, São Paulo, v. 10, n. 2, pp. 274-295, 2021 


\section{artigos}

Ananda Mendes Lima

pelos arquivos.

O objetivo deste estudo é discorrer sobre as ações de difusão do Centro de Memória - Unicamp (CMU) e como elas se enquadram dentro das teorias arquivística. Pretende-se também refletir se tais medidas atendem aos pontos relacionados à difusão, educação patrimonial, democratização do acesso aos documentos e contribuição à divulgação científica. Para tanto, serão expostas as discussões teóricas sobre a difusão, compreendendo o que é, e qual o seu papel dentro da arquivística com base em estudos recentes, como o de Marcelo Chaves (2020), Moisés Rockembach (2015), Gláucia Vaz e Renato Pinto (2018), entre outros. Prosseguindo, será introduzido o Centro de Memória, com seu histórico, estrutura e área de atuação, seguido da apresentação das atividades de difusão que estão em curso ou planejadas.

\section{Difusão}

A difusão, apesar de ser considerada por muitos teóricos da arquivística (ROUSSEAU e COUTURE, 1998; ALBERT I FUGUERAS, 2001; BELLOTTO, 2006; apud PARRELA, 2020) um campo basilar dentre as funções do arquivo, recebe uma atenção secundária dentro dos estudos do campo (PARRELA, 2020, p. 10). Chaves, em O papel da difusão para o fortalecimento da identidade do arquivo (2020), apresenta reflexões críticas sobre o papel da difusão dentro dos arquivos e os lapsos que a teoria arquivística possui. Entre os argumentos do autor, chamo a atenção para a ausência de definição específica para o termo "difusão". Em suas palavras:

De modo geral, percebe-se a existência de uma lacuna na literatura arquivística quanto à definição do termo "difusão". Ressalva-se que há pesquisas sobre a função de difusão na área, porém, ainda são escassas as investigações que aprofundam essa questão. Os autores da área tendem a utilizar o termo difusão, disseminação e divulgação indistintamente, em grande parte das produções científicas consultadas, embora os sentidos que lhes são atribuídos não correspondam, necessariamente, aos conceitos estabelecidos na Ciência da 


\section{artigos}

\section{Difusão em Arquivos e o centro de memória - Unicamp}

Informação. (CHAVES, 2020, p. 80)

Como mencionado no excerto, mesmo sem uma definição específica, há estudos que tem como foco a difusão. Apesar de poucos, é possível notar um aumento da abordagem sobre o tema nas últimas duas décadas, algumas das quais descreverei as principais ideias. Começando por Chaves que, no artigo já citado (CHAVES, 2020, p. 7792) questiona como avaliar a efetividade das medidas de difusão, quais os limites para os meios de atrair público ao arquivo, como lidar com possíveis hierarquizações de acesso ao documento, entre outros fatores. O autor defende que a difusão deve ir além da divulgação do arquivo com fins históricos, uma vez que a historiografia já se encarrega disso, devendo se voltar também às atividades do arquivo.

Entre as preocupações de Chaves está o nível de erudição dos produtos do arquivo que, diferente de outras entidades, como museus, não se conectam através dos "mecanismos sensoriais mais imediatos dos visitantes" (CHAVES, 2020, p. 82), sendo requisitado uma maior perseverança para usufruto dos seus bens. Para o autor, a difusão tem como princípio a divulgação da instituição, seus trabalhos técnicos e científicos, seu acervo e a identidade do arquivo (CHAVES, 2020, p. 84). Por fim, defende com base em estudos de Bruno Delmas (2010, p. 85) que as ações do arquivista devem ser autocentradas, apartadas das influências da historiografia e outros campos do saber, mas sem deixar de levá-los em conta.

Escrevendo para a mesma edição da Revista do Arquivo São Paulo, Ivana Denise Parrela, no artigo Difusão do Arquivo - comunicação, mediação e ações educativas e culturais, apresenta as diferentes definições de difusão para alguns estudiosos (ALDABALDE e RODRIGUES, 2015, p. 259; BARBOSA e SILVA, 2012, p. 46; CHABONNEAU, 1999, p. 374-375; e outros). É possível notar uma preocupação com a transmissão das características das instituições, com o acesso à cultura e com a divulgação científica de qualidade. Parrela ressalta a forma como, ao tratar de difusão, leva-se em conta meios 


\section{artigos}

Ananda Mendes Lima

técnicos padronizados fundamentados nas discussões do Conselho Internacional de Arquivos, permitindo uma conexão entre as diversas entidades arquivísticas nacionais e internacionais. Evidencia também o papel das novas tecnologias da informação, que trazem inovações para o acesso e interação com a documentação (PARRELA, 2020, p. 10).

Moisés Rockembach (2015) indica a necessidade de uma mediação entre o produto a ser divulgado e o consumidor. Defende que apenas a digitalização, tendo em vista as novas plataformas comunicacionais, não é suficiente para a informação e acesso à cultura com qualidade ${ }^{1}$. Assim como Chaves, ao observar o Dicionário Brasileiro de Terminologia Arquivística (2005), percebe a ausência do termo, que pode ser compensada, segundo o autor, nas definições de “Disseminação da Informação" e “Divulgação"2.

Em seu Trabalho de Conclusão de Curso: Ações de difusão do acervo arquivístico

\footnotetext{
1 Ana Maria Camargo, em entrevista concedida ao SESC SP, também realiza crítica à digitalização esvaziada de sentido, como segue: "A maioria das instituições, no entanto, escolhe o caminho mais curto para disponibilizar, para usuários internos e externos, os documentos de seus acervos: o da digitalização selvagem. É mais fácil digitalizar tudo, por mais caro que seja esse processo, do que criar metadados pertinentes para a documentação sob custódia de um centro de memória. Como os arquivos públicos não têm investido em instrumentos de pesquisa que apontem para o potencial informativo das séries ali conservadas, optando por apresentá-las em quilométricas relações de imagens digitais, resta saber se têm de fato alimentado trabalhos acadêmicos novos... Acho difícil." (CAMARGO, 2019, p. 35)

2 “O Dicionário Brasileiro de Terminologia Arquivística (2005) não traz o termo 'difusão', mas se aproxima quando conceitua Disseminação da Informação, que segundo ele é o "fornecimento e difusão de informações através de canais formais de comunicação" (ARQUIVO NACIONAL BRASIL, 2005, p.71). Também traz o termo Divulgação que é o "Conjunto de atividades destinadas a aproximar o público dos arquivos, por meio de publicações e da promoção de eventos, como exposições e conferências" (ARQUIVO NACIONAL BRASIL, 2005, p.72). Deste público podem fazer parte tanto o usuário, que é a "pessoa física ou jurídica que consulta arquivos. Também chamada consulente, leitor ou pesquisador" (ARQUIVO NACIONAL BRASIL, 2005, p.169), quanto outros interessados que desconheçam a existência do arquivo, que dependerão de atividades de promoção do mesmo para tomarem conhecimento." (ROCKEMBACH, 2015, p. 100)
} 


\section{artigos}

\section{Difusão em Arquivos e o centro de memória - Unicamp}

do Arquivo Nacional do Brasil (2018), Angélica do Carmo Coitinho defende o arquivo como um espaço que vai além da guarda dos documentos, sendo a "divulgação através de ações educativas e culturais" (COITINHO, 2018, p. 1) uma das principais funções da instituição. Nas palavras de Coitinho, essas tarefas ainda vão além:

É preciso que os arquivistas realizem todas as funções arquivísticas, especialmente a difusão, entendida não somente como a disponibilização de guias, catálogos e outros instrumentos de pesquisas ao usuário, mas também a divulgação desse acervo de forma que o cidadão possa participar do processo de construção do conhecimento. (COITINHO, 2018, p. 29)

Railane Pereira (2017), Andresa Barbosa e Haike da Silva (2012) e Gláucia Vaz e Renato Venâncio (2018) trazem outras visões da difusão em acervos, focando na educação, educação patrimonial, marketing e comunicação. Pereira trata a difusão como parte da educação patrimonial, com seu viés cultural. Para tanto, seriam necessárias ações frequentes e sistemáticas, que colocassem em contato a população, os pesquisadores e as equipes técnicas dos arquivos com um tratamento interdisciplinar, possibilitando a identificação dos alunos e a comunidade com o patrimônio arquivístico e a história (PEREIRA, 2017, p. 4). Barbosa e Silva consideram a difusão como essencial ao arquivo e seu compromisso social, defendendo que a função do arquivo não se restringe à guarda do documento. Dessa forma, é indispensável uma relação próxima entre as atividades do arquivo e o ensino (BARBOSA e SILVA, 2012, p. 51 - 57). Já Vaz e Venâncio propõem uma perspectiva que relaciona o marketing à difusão, colocando o público do acervo como consumidor e refletindo sobre a conexão entre o que ele precisa e espera e o que as entidades oferecem, sem deixar de lado o questionamento sobre os limites de tal abordagem (VAZ E VENÂNCIO, 2018, p. 8 - 22).

Entre os pontos em comum nos estudos apresentados está a necessidade das entidades arquivísticas, ao trabalharem com difusão, ir além dos instrumentos de pesquisa sem perder a identidade da instituição. Assim, defendem a Epígrafe, São Paulo, v. 10, n. 2, pp. 274-295, 2021 


\section{artigos}

Ananda Mendes Lima

interdisciplinaridade. Outro fator presente nos estudos é a recomendação de análise do público da instituição e, com base nos resultados, desenvolver propostas que contemplem o usuário, pensando na acessibilidade da informação. Apontam ainda a ausência de políticas públicas sistematizadas em um cenário mais amplo, como o nacional, delegando a atuação educativa dos arquivos a ações pontuais.

As análises do papel da difusão divergem sobre considerá-la uma peça fundamental do arquivo ou um aspecto secundário. No Brasil, uma das principais defensoras da difusão como área secundária é Heloísa Bellotto (2006, p. 227 apud PEREIRA, 2017, p. 7) que, dentre o tripé das principais atividades: gestão, preservação e acesso (CHAVES, 2020, p. 79), a difusão se encontra como um setor subordinado ao acesso. Entretanto, excluí-la dos componentes principais da tríade arquivística não implica em eliminar sua importância. Chaves (2020, p. 79) aponta como Bellotto defende esse caráter secundário por acreditar que, se bem desenvolvidas, as três atividades irão suprir as necessidades de atendimento, sem demandar um setor específico de difusão.

Em contrapartida, Rousseau e Couture (1998), traduzem a função do arquivo em quatro tarefas: tratamento, conservação, criação e difusão; que se desdobram ainda em difusão, criação, avaliação, aquisição, conservação, classificação e descrição (ROUSSEAU e COUTURE, 1998, p. 265, apud ROCKEMBACH, 2015, p. 100). Dessa forma, a difusão é considerada não apenas uma auxiliar, mas um dos componentes essenciais ao bom funcionamento do arquivo. Outros teóricos (ROCKENBACH, 2015; PEREIRA, 2017; COSTA, 1998; PARRELA, 2020) também defendem a difusão como um dos pilares das instituições arquivísticas, com argumentações que giram em torno da acessibilidade como direito e do caráter público dos documentos de arquivo. Como exemplo, apontam Barbosa e Silva: 


\section{artigos}

\section{Difusão em Arquivos e o centro de memória - Unicamp}

Entendemos que a difusão deve ser colocada entre as prioridades, uma vez que é através dela que a sociedade conhece o patrimônio documental. Não tratamos aqui apenas da questão de prover o acesso aos documentos para aqueles que os buscam. (...) É por meio da difusão que se dá visibilidade às fontes, antecipando ao público a riqueza documental de um arquivo. Sua importância está em chamar a atenção para o que está guardado; em um arquivo público, em dar publicidade ao que já é público, mas que muitos não conhecem; em construir, através do conhecimento desse patrimônio, a noção do seu valor. Com atribuições de tamanha importância, acreditamos que a difusão é apenas uma dentre as ações que devem ser colocadas em primeiro plano nas políticas institucionais dos arquivos, como parte de uma relação de interdependência entre recolhimento, custódia, preservação e gestão documental. (BARBOSA E SILVA, 2012, p. 46)

Assumindo a difusão como parte das funções primárias do arquivo, surge a reflexão: a difusão deve ser pensada para quem? E, dentro disso, deve haver hierarquização para acesso ao acervo? Para refletir sobre as questões, serão articulados de forma sucinta dois argumentos: o de Célia Leite Costa (1998), que defende o acesso à informação como componente dos direitos humanos; e o de Marcelo Chaves (2020), que coloca as dificuldades financeiras como fator decisivo na opção por hierarquizar o acesso ao arquivo.

Partindo da noção de público e privado e considerando que o "público hoje está muito mais próximo da ideia de social e de coletivo" (COSTA, 1998, p. 190), Célia Costa recupera as mudanças com o decorrer do tempo do valor atribuído aos documentos pelos historiadores. A autora assume a documentação dos arquivos como, em primeiro lugar, históricas, independentemente de estar sob custódia de entidades públicas ou privadas. Costa aponta os acontecimentos da Segunda Guerra Mundial e o direito à informação, com a Declaração Universal dos Direitos Humanos como garantia para que o conteúdo dos arquivos não mais seja de acesso exclusivo aos historiadores, mas sim a todos os cidadãos interessados. Em suas palavras:

O direito à informação é, portanto, um dos mais novos direitos do homem. Consiste em poder receber informações e difundi-las sem restrições, e também na possibilidade de opinar e de se exprimir livremente. Como se pode observar, tal direito está vinculado à liberdade de opinião e expressão, que integra as 


\section{artigos}

\section{Ananda Mendes Lima}

liberdades públicas tão caras à Grécia antiga e que foi posteriormente restaurada pela ilustração. Dar acesso à informação significa tornar público, transparente, visível, algo antes obscuro, secreto ou simplesmente ignorado pela coletividade. Nesse sentido, o direito à informação é fundamental ao exercício das liberdades públicas e ao pleno desenvolvimento dos sistemas políticos democráticos (COSTA, 1998, p. 192)

Costa argumenta que, embora existam arquivos privados, seus componentes são de interesse comum e, portanto, devem ser acessíveis. Traz ainda a questão dos segredos de estado e do direito à privacidade. Propõe que, após o período necessário para cada caso em particular, devem tornar-se públicos, de forma que ao mesmo tempo em que o exercício da cidadania seja pleno, não se abra mão "do respeito à privacidade e à vida reservada dos sentimentos" (COSTA, 1998, p. 197).

Ainda que não se posicione contra os argumentos acima expostos, Chaves (2020, p. 56 -58) apresenta outra perspectiva sobre a acessibilidade. Pensando na realidade brasileira, onde nem sempre os arquivos recebem os auxílios financeiros e estruturais necessários para uma realização plena de suas funções, coloca a hierarquização da prioridade de acesso ao conteúdo dos arquivos como uma possível solução para a problemática. Assim, os pesquisadores ficam em primeiro lugar e a comunidade em segundo, submetendo do mesmo modo as atividades de difusão à tal hierarquia. Posto isto, é necessário refletir como manter uma política de difusão efetiva, que atinja o maior público possível, garantindo o direito à informação dentro das condições do arquivo, sem diminuir o investimento em outros aspectos basilares da instituição.

Difusão, para além do conteúdo historiográfico, é uma preocupação constante nos estudos arquivísticos. Entre eles o de Chaves (2020) e Pereira (2017), já mencionados. O argumento dos autores aponta uma ênfase excessiva na epistemologia histórica no arquivo. Defendem que “divulgar o conhecimento histórico baseado em documento de arquivo apenas não basta" (CHAVES, 2020, p. 79), uma vez 


\section{artigos}

\section{Difusão em Arquivos e o centro de memória - Unicamp}

que a arquivologia é um campo rico teórica e metodologicamente. Além disso, o conhecimento dos processos técnicos e metodologia aos quais o documento é submetido pode ocasionar mudança na perspectiva e até mesmo valorizar o ofício científico.

No caso do grande público, entender esse processo leva a reflexão e conscientização sobre a preservação da memória, além de trabalhar uma problemática apontada por Eddy Put: o analfabetismo documental (PUT, 2020, p. 76). Esse obstáculo se impõe não apenas a comunidade, mas também ao pesquisador que, por não conhecer as dinâmicas internas de um arquivo, tem dificuldade ao se deparar com seu acervo e instrumentos. O autor sugere uma "reeducação" do cidadão para interação com essas entidades, mas também uma mudança nos serviços que contemple essa lacuna. Dessa forma, para além de construir junto ao público o conhecimento por trás das instituições, colaboraria para suprimir a visão da arquivística como uma ciência auxiliar, demonstrando a complexidade e particularidades de seu próprio campo disciplinar.

Apesar dos argumentos acima expostos, a História e Arquivologia andam lado a lado. Por conseguinte, a atuação dos historiadores dentro do arquivo é de grande valia. A Associação Nacional de História - ANPUH, no documento: O perfil profissional dos historiadores atuantes em arquivos (2012), resultado do evento de mesmo nome, defende que "a presença de historiadores é imprescindível ao bom funcionamento dessas entidades custodiadoras" e destaca "a importância da inclusão de disciplinas e atividades voltadas ao tema nos currículos dos cursos de História a fim de que esses possam qualificar e aprofundar a formação de profissionais capazes de atuar em arquivos e entidades congêneres" (ANPUH, 2012, p. 3). A associação alega que a pesquisa histórica em arquivos pode se voltar tanto ao acervo e questões técnicas de seus conjuntos documentais quanto ao seu conteúdo histórico. Quanto à difusão: 
Ananda Mendes Lima

(...) a participação do historiador torna-se fundamental sempre que o produto de difusão cultural envolva análise e narrativa histórica, já que é a sua formação profissional específica que o capacita a contribuir com competências como: atenção a múltiplas temporalidades; capacidade de crítica, contextualização e interpretação de documentos e de seus produtores; atualização historiográfica; capacidade de relacionar história acadêmica e história ensinada, e história e memória, respeitando referenciais teórico-metodológicos próprios da História. (ANPUH, 2012, p. 7)

Enunciadas as bases teóricas sobre as quais a difusão se apoia, cabe destacar os posicionamentos do CMU quanto às problemáticas. De forma concisa, espera-se que as medidas de difusão tenham como objetivo não apenas a publicação de temática histórica partindo dos documentos do acervo, mas a divulgação da identidade da instituição, incluído as complexidades do trabalho no arquivo. A proposta de difusão é desenvolvida em conjunto com o processamento técnico, de forma que um não se sobressaia ao outro, com um diálogo interdisciplinar considerando a difusão como um dos pilares da instituição. Espera-se que atinjam um público amplo, desde estudantes do ensino básico, estudantes universitários, pesquisadores, comunidade e profissionais de arquivo. Assim, através de ações variadas que serão explanadas no decorrer deste estudo, a expectativa é contribuir para divulgação de saberes diversos, de qualidade, comprometidos com a ciência e democratização do acesso ao conhecimento. Posto isto, cabe conhecer um pouco mais sobre o $\mathrm{CMU}$.

\section{O Centro de Memória - Unicamp}

O Centro de Memória - Unicamp (CMU) surgiu em 1985 como iniciativa do professor Dr. José Roberto do Amaral Lapa, junto à Universidade Estadual de Campinas (Unicamp). O estopim para sua efetivação foi o episódio da destruição de milhares de documentos do Tribunal de Justiça do Estado de São Paulo, Comarca de Campinas, solução que seria dada pelo Fórum de Campinas ao problema crônico da falta de espaço físico para a guarda deste acervo. Desde então, ao longo dos anos o Centro se 


\section{artigos}

\section{Difusão em Arquivos e o centro de memória - Unicamp}

tornou um importante referencial de documentações relacionadas à cidade de Campinas e região, reunindo conjuntos públicos e privados (pessoais e institucionais). O CMU faz parte da Coordenadoria de Centros e Núcleos Interdisciplinares de Pesquisa (Cocen), vinculado à Coordenadoria Geral da Unicamp e "é responsável pela captação, organização, preservação, disponibilização e difusão (...) assim como à produção de pesquisas e publicação de livros e periódicos de caráter interdisciplinar, com ênfase na articulação entre memória e história" (CENTRO de Memória - Unicamp, 2018, p. 2).

Desde sua fundação, se organizou em setores que atuavam segundo o gênero documental. Em 2015, houve reformulação da proposta, quando o CMU passou a se dividir em processamento técnico, digitalização e conservação e restauro, responsáveis pelos Arquivos Históricos, e a biblioteca "José Roberto do Amaral Lapa", nomeada em homenagem ao seu fundador e primeiro diretor do centro, especializada em Campinas. O acervo histórico possui cerca de 137 conjuntos, que se estendem do século XVIII aos dias atuais, com os mais diversos temas relacionados à história de Campinas e região, e suportes: textuais, iconográficos, tridimensional, audiovisual, etc. (CENTRO de Memória - Unicamp, 2018, p. 3). As principais linhas que compõem a política de incorporação de conjuntos, segundo as políticas do acervo (CENTRO de Memória Unicamp, 2018, p. 4 - 6) são: memória, cidade e sensibilidades; cidade, história e interdisciplinaridade; história econômica e social de Campinas e do Oeste Paulista e, como subtemas: o trabalho e suas relações; manifestações culturais e sociabilidades; história das ciências e práticas de saúde; e o homem e suas relações para com o meio.

As ações de difusão do CMU envolvem o público acadêmico e profissionais da área de arquivo, através de publicações de periódicos, livros, catálogos e eventos, e também o público escolar e a comunidade, através de visitas guiadas pelo acervo e exposições físicas e virtuais. Outro grupo que se relaciona com o CMU são os estudantes de graduação, através de projetos de estágios. Entre esses projetos, a 


\section{artigos}

Ananda Mendes Lima

curadoria de exposição virtual na plataforma Google Arts \& Culture ${ }^{3}$ e produção de conteúdo para o site Difusão ${ }^{4}$, voltado à história de Campinas. Em 2020, novas propostas estão em desenvolvimento, visando atingir maior e mais diversificado público na região e expandir o diálogo com outras instituições. As plataformas digitais serão os principais alvos para as medidas, através de publicações textuais, encontros, vídeos, podcasts e exposições, que serão detalhadas a seguir.

O site Difusão, já mencionado, teve sua iniciativa através de disciplina de estágio obrigatório do curso de História da Unicamp, em 2019, quando foram desenvolvidas diversas produções textuais com suporte no arquivo histórico e biblioteca. O site viabiliza a divulgação de conteúdo sobre a história regional. O uso da documentação disponível no CMU e da bibliografia evidencia diversos agentes e perspectivas históricas.

O conteúdo do site se divide em quatro setores: “Nosso acervo" - trabalhando um ou mais conjuntos, seu conteúdo e possibilidades de pesquisa a partir dos mesmos; "Por dentro do tema" - desenvolvendo produção referente a cidade de Campinas e região, com base no acervo histórico; "Sugestão pedagógica" - recomendações para uso de documentos do Centro de Memória em sala de aula; e "Pesquise Campinas" levantamento bibliográfico com a temática da cidade, alguns com resumos expandidos. Apesar de ter iniciado com a disciplina de estágio, o portal será alimentado com produções continuas.

\footnotetext{
${ }^{3}$ Disponível em: <https://artsandculture.google.com/partner/centro-de-memoria-unicamp>. Acessado em 01 Setembro 2020

${ }^{4}$ Disponível em <www.difusaocmu.com.br>. Acessado em 01 Setembro 2020
} 


\section{artigos}

\section{Difusão em Arquivos e o centro de memória - Unicamp}

A série de cartilhas "Por dentro da história" ${ }^{5}$ consiste em três volumes, sendo o público-alvo estudantes do ensino fundamental I e II, Ensino Médio e professores. As cartilhas buscam apresentar temas relacionados ao patrimônio cultural (volume 1: Patrimônio Cultural Material; volume 2: Patrimônio Cultural Imaterial; volume 3: Memória e Identidades Culturais), enfatizando sua presença na cidade de Campinas de forma lúdica, através de atividades e passatempos que exercitam diversas habilidades. O objetivo das cartilhas é auxiliar a identificação dos usuários com o patrimônio e com a história do meio em que habitam, reconhecendo sua pluralidade cultural. Essa percepção do indivíduo como agente histórico e membro de um grupo diverso estimula a ação no sentido de preservá-lo.

O desenvolvimento e participação em eventos, tendo em vista a particularidade do período de pandemia de 2020, vêm sendo realizados de forma remota. Entre eles, o Il Colóquio Gestão do Patrimônio Cultural: o papel das instituições na preservação da memória local, organizado pelo CMU em comemoração de seus 35 anos, e a $4^{\text {a }}$ Semana Nacional de Arquivos: empoderando a sociedade do conhecimento, ocasião da publicação do primeiro volume da cartilha "Por Dentro da História" (BERTO org., 2020), série de vídeos sobre conservação e exposições virtuais. A participação e promoção de eventos auxilia a divulgar o que é produzido pelo Centro e a comunicação e troca de experiência com outras entidades.

As exposições virtuais realizadas pelo Centro de Memória se encontram na plataforma Google Arts \& Culture, que possibilita o uso de imagens, textos e outras ferramentas de comunicação. Entre os aspectos positivos da plataforma, está a publicação em dois idiomas (português e inglês), viabilizando alcance de público além do nacional. As exposições remetem à história do município e evidenciam o caráter

\footnotetext{
${ }^{5}$ https://www.cmu.unicamp.br/index.php\#!html/conteudo.html?c=72 Epígrafe, São Paulo, v. 10, n. 2, pp. 274-295, 2021
} 


\section{artigos}

Ananda Mendes Lima

dinâmico das instituições de arquivo, apresentando seu conteúdo de forma acessível à comunidade.

Através de publicações digitais especializadas, outra iniciativa para divulgação do acervo e de trabalhos que partem dele são os instrumentos de pesquisa, que podem ser catálogos seletivos, cadernos técnicos e outros. O primeiro dos instrumentos produzidos nessa nova iniciativa de difusão foi o Catálogo Seletivo Bertha Lutz no Acervo CMU, a ser disponibilizado no portal da instituição. O catálogo reúne documentos que demonstram as relações políticas e movimentação pelos direitos das mulheres do início do século XX por Bertha Lutz e sua relação com o senador Adolpho Affonso da Silva Gordo ${ }^{6}$. A importância da documentação levou à inclusão na candidatura conjunta "Feminismo, ciência e política - o legado Bertha Lutz, 1881-1985", para o programa Memória do Mundo, da UNESCO.

As redes sociais, como Facebook, Instagram, Twitter e Youtube, são foco dos mais diversos modelos de publicação, visando atingir público amplo. Os produtos envolvem efemérides, a história campineira, o acervo e questões técnicas do arquivo. Em formato de vídeo, para plataformas como o YouTube, as séries “Conservação em casa" tratando, como o nome diz, de técnicas de conservação, "Quem pesquisa o quê?", interações com pesquisadores que utilizaram documentação do CMU compartilhando suas experiências e a série "Arquivo Vivo" que trata assuntos referentes à arquivologia. Por último, podcasts disponibilizado em plataformas diversas, como a série "Um arquivo de..." que, além do Centro de Memória, discorre sobre diferentes instituições e arquivos, com suas temáticas e especificidades. As produções para o YouTube e os

\footnotetext{
${ }^{6}$ Os documentos utilizados no desenvolvimento do catálogo se referem à subsérie Sistema Eleitoral, do conjunto Adolpho Affonso da Silva Gordo. A subsérie é composta por recortes de periódico, cartas, telegramas e outros suportes, que demonstram as relações entre Lutz e Gordo na luta parlamentar pelos direitos das mulheres, em especial o direito ao voto.
} 


\section{artigos}

\section{Difusão em Arquivos e o centro de memória - Unicamp}

podcasts tem como objetivo apresentar a identidade da instituição, estabelecer conexões com outras entidades e profissionais e possíveis abordagens para os conteúdos do acervo.

As propostas foram desenvolvidas por uma equipe de difusão, composta por bolsistas, estagiários e funcionários, interligada ao processamento técnico. Vale apontar que, tendo em vista o comprometimento com a qualidade dos serviços desenvolvidos, a equipe do CMU realiza debates frequentes com temas relacionados à arquivista, história e memória, com a intenção de aprimoramento das atividades, de reflexão e embasamento teórico das práticas que envolvem o trabalho no arquivo. A equipe é composta por profissionais e estudantes de diversas áreas, o que contribui para o debate interdisciplinar sobre o ofício. É possível acompanhar as publicações já desenvolvidas no portal online do Centro de Memória ${ }^{7}$ e através das redes sociais ${ }^{8}$.

Como exposto, o acesso à informação é considerado um direito civil. Dessa forma, a acessibilidade do acervo ao público faz parte dos deveres da instituição. Indo além, é possível notar nas medidas desenvolvidas e planejadas para difusão do acervo histórico do CMU uma preocupação não apenas com a disponibilização, mas sim com uma difusão de qualidade. Entendendo a afirmativa de Chaves (2020, p. 82) de que o documento de arquivo possui um alto nível de erudição, concordamos que apenas digitalizar e divulgar não é suficiente, uma vez que faltariam suportes para interpretação e identificação com o que é apresentado. Portanto, trabalhar com

\footnotetext{
${ }^{7}$ Disponível em <www.cmu.unicamp.br>.Acessado em:

${ }^{8}$ Disponível em <https://www.facebook.com/CentroDeMemoria;>.Acessado em:

Dispovível em: < https://www.instagram.com/centrodememoriaunicamp/;

https://open.spotify.com/show/40mk3cUsb3q3UKNzZt3Gvp?si=-T0xmBC7RYeX_EDGjluH9Q;>Acessado em:
}

Disponível em: <https://www.youtube.com/channel/UCiBt4axBCWyeK5ZruTM3v2w>.Acessado em: 
Ananda Mendes Lima

temáticas teóricas e metodológicas em linguagem diversificada é uma maneira de atingir o público não acadêmico e aprofundar o conhecimento técnico dos profissionais e estudantes envolvidos no meio.

Outro dentre os aspectos basilares levados em consideração no desenvolvimento do planejamento da difusão é a educação patrimonial, envolvendo o patrimônio arquivístico, histórico e cultural em seus diversos pormenores. 0 documento valoriza a pluralidade cultural, considerando o arquivo público, como apontam Vaz e Venâncio: “um instrumento para o desenvolvimento do sujeito crítico, de compreensão do patrimônio, memória e história coletiva, trata-se de um espaço para a promoção de cidadania e para a conscientização do que é democracia." (VAZ E VENÂNCIO, 2018, p. 25 - 26). A difusão dá visibilidade ao patrimônio, aproximando-o da comunidade e auxiliando a entender e contextualizar suas próprias bases culturais dentro de seu bairro, município e região, o que possibilita que exercite essa habilidade ao analisar de forma crítica as relações sociais, econômicas, políticas e culturais.

De acordo com a perspectiva de Railane Pereira do patrimônio como linguagem “pela qual aquela/uma sociedade se comunica e partilha seus referencias (...) é necessário ensinar a leitura desses espaços patrimoniais." (PEREIRA, 2017, p. 4). Assim, pensando no ensino básico, é esperado com as propostas de difusão voltadas a esse público estimular que o estudante se perceba como sujeito na história e reconheça a pluralidade dos agentes. Essas concepções estão presentes também no documento de diretrizes curriculares da educação básica para o ensino fundamental (GODOY, 2012), que propõe ao estudante tecer ligações entre o ensino e o seu cotidiano ao tratar o conteúdo partindo do seu meio, valorizando "a memória histórica e o conhecimento de seu espaço imediato" (GODOY, 2012, p.111).

Afora os instrumentos produzidos para difusão, o CMU vem disponibilizando 


\section{artigos}

\section{Difusão em Arquivos e o centro de memória - Unicamp}

acesso ao seu acervo online, através de página na plataforma Access to Memory Ato $^{9}$. O AtoM é um repositório em código aberto, desenvolvido com o objetivo de incentivar o uso das normas internacionais da arquivística por parte dos arquivos definitivos. Nele é possível acessar os conjuntos já disponíveis, com sua descrição e outras características técnicas, assim como a digitalização na íntegra da documentação. A iniciativa é um esforço positivo e também permite trazer à tona a problematização da preservação dos conteúdos digitais.

Em coluna para o jornal O Estado de São Paulo, Edmundo Leite (2020), com base na restrição por parte do governo brasileiro no acesso aos dados sobre a epidemia do coronavírus, aponta a "fragilidade da preservação digital". O autor mostra a falta de garantias, seja da iniciativa pública ou privada, de manutenção da disponibilidade das informações em meios digitais, defendendo que por ora a única opção é a ação de preservação individual. Pontua o paradoxo de, "em plena era digital", os documentos físicos ainda serem a "única garantia de preservação de dados". A questão se relaciona diretamente às políticas de preservação documental brasileiras que, mesmo em relação aos documentos com suporte físico, estão, como aponta Costa, em um “atraso secular" (COSTA, 2020, p. 196). Segundo a autora:

O atraso secular em termos de uma legislação específica para arquivos no Brasil explica, por exemplo, a fragmentação e a perda total ou parcial de fundos que deveriam integrar O patrimônio documental brasileiro (Costa, 1997: 181). É preciso, portanto, criar uma nova mentalidade com relação à importância e à utilização das informações provenientes de documentos de arquivos. (Costa, 2020, p. 196)

Muitos dos projetos são novos campos de ação para o Centro de Memória. Assim, ainda não é possível verificar efetivamente seu aproveitamento. Apesar disso, é importante a realização periódica de relatórios que avaliem se estão atingindo os

\footnotetext{
${ }^{9}$ Disponível em:<www.atom.cmu.unicamp.br>. Acessado em:

Epígrafe, São Paulo, v. 10, n. 2, pp. 274-295, 2021
} 
Ananda Mendes Lima

objetivos propostos. Observando as medidas que estão provendo resultados positivos ou não, podemos replanejar para manter um serviço de qualidade, atendendo às necessidades da comunidade, sem perder de vista as demandas do arquivo.

Diversos aspectos podem ser observados para a realização de diagnósticos dos planos de difusão. Entre eles, estão as interações nas redes sociais, quais os tipos de interações, qual público está acessando o conteúdo, qual o alcance dos produtos, se houve ou não aumento nas buscas e pedidos de buscas do acervo, etc. De início, a avaliação será através do desenvolvimento de relatórios com os dados apontados através das análises dos gráficos de acesso disponibilizados pelas redes sociais. Para as demais plataformas, ainda estão em estudo as ferramentas que serão utilizadas.

\section{Considerações finais}

Os arquivos, centros de memória e outras instituições de guarda, abrem espaço para uma abordagem interdisciplinar, que enriquece, o debate científico e disponibiliza acesso à informação de qualidade. Diversas instituições, como o CMU, vêm agindo para possibilitar maior acessibilidade à objetos outrora restritos a pesquisadores. Dessa forma, o recorrente debate sobre a falta de diálogo entre a academia e a comunidade pode encontrar um caminho para solução no arquivo, que busca abrir espaço para conteúdos com comprometimento metodológico e científico de forma interdisciplinar. É de grande importância que a teoria arquivística, assim como as questões técnicas que envolvem as instituições de arquivo, se tornem componente fundamental dos cursos de graduação, o que pode acarretar tanto na melhoria do diálogo entre comunidade e academia quanto na pesquisa que, familiarizada com a arquivística, gera um novo olhar sobre suas fontes.

Apesar de não ser o principal foco dos estudiosos da teoria arquivística, é 


\section{artigos}

\section{Difusão em Arquivos e o centro de memória - Unicamp}

possível notar um aumento na literatura sobre difusão e a necessidade de heterogeneizar o acesso ao acervo. Essa tendência está diretamente ligada à ideia do arquivo como uma entidade viva e dinâmica, que se modifica e adapta às demandas de seu tempo. Ainda, as medidas estão de acordo com a crítica de Ana Maria Camargo (CAMARGO, 2019) sobre uma possível superficialidade dos centros de memória com o objetivo de ir contra a ideia do arquivo como um espaço "velho, inservível, lúgubre, reduto da burocracia" (CAMARGO, 2019, p. 33).

Portanto, as novas propostas de difusão do CMU têm como objetivo mostrar que o centro de memória, ao mesmo tempo que possui grande relevância em seu conteúdo documental e arquivístico, segue as demandas de pesquisadores e do público geral. Possibilitando, através de diversos meios a conscientização do cidadão e da comunidade de que aquele também é um espaço seu, viabilizando, de fato, o seu usufruto.

\section{Referências bibliográficas}

ALBERCH i FUGERAS, Ramón; BOIX, Lurdes; NAVARRO, Natália; VELA, Susanna. Archivos y cultura: manual de dinamización. Gijón: Ediciones Trea, 2001.

ALDABALDE, Taiguara Villela; RODRIGUES, Georgete Medleg. Mediação cultural no Arquivo Público do Estado do Espírito Santo. Transinformação. Online, v. 27, n. 3, 2015. Disponível em: <https://www.scielo.br/scielo.php?pid=S0103-

37862015000300255\&script=sci_abstract\&tlng=pt> Acesso em: 15 jul. 2020

ANPUH. O perfil profissional dos historiadores atuantes em arquivos: documento final do encontro. São Paulo, 2012. Disponível em: http://apalopez.info/bieau/ANPUHhistoriadores_em_arquivos.pdf> Acesso em: 15 jul. 2020.

ARQUIVO NACIONAL (BRASIL). Dicionário brasileiro de terminologia arquivística. Rio de Janeiro: Arquivo Nacional, 2005.

BARBOSA, Andresa Cristina Oliver; SILVA, Haike Roselane Kleber da. Difusão em Arquivos: Definição, políticas e implementação de projetos no Arquivo Público do 


\section{artigos}

\section{Ananda Mendes Lima}

Estado de São Paulo. Rio de Janeiro: Acervo, v. 25, n. 1, 2012.

Arquivos permanentes: tratamento documental. 4. ed. Rio de Janeiro: Editora FGV, 2006.

BERTO, João Paulo (org.) BERTO, Ana Cláudia Cermaria [et. Al.]. Por dentro da história: cartilha sobre o patrimônio cultural de Campinas - Patrimônio Cultural Material. Série: Por Dentro da História v.1. Campinas, SP: Centro de Memória - Unicamp, 2020.

CAMARGO, Ana Maria. Os centros de memória são instrumentos de ação (entrevista concedida a Carla Lira, Gabriel Vituri, João Paulo Guadanucci e Marta Raquel Colabone). In: Cadernos Sesc de Cidadania, v. 10, 2019.

CENTRO de Memória - Unicamp. Política de Acervo. Campinas/SP, 2018. Disponível em: <https://www.cmu.unicamp.br/admin/arquivos/paginas/POLITICA_DE_ACERVO_CMU_f inal.pdf>. Acesso em: 15 jul. 2020.

CHARBONNEAU, Normand. La diffusion. In : COUTURE, Carol (Colab.). Les fonctions de I' archivistique contemporaine. Québec: Presses de I' Université du Québec, 1999.

CHAVES. O giro conceitual e de prática no programa de difusão do Apesp. São Paulo: Revista do Arquivo São Paulo, Ano VI, n. 10, 2020.

CHAVES. O papel da difusão para o fortalecimento da identidade de arquivo. Revista do Arquivo São Paulo, Ano VI, n. 10, 2020.

COITINHO, Angélica do Carmo. Ações de difusão do acervo arquivístico do Arquivo Nacional do Brasil. Rio de Janeiro, 2018.

COSTA, Célia Leite. Intimidade versus Interesse Público: a Problemática dos Arquivos. Revista Estudos históricos. v. 11, n. 21, 1998. disponível em:

< bibliotecadigital.fgv.br/ojs/index.php/reh/issue/view/287> Acesso em: 20 jul. 2020.

D'AVILLA, Cristiane. Algumas experiências de difusão de arquivo na casa de Oswaldo Cruz/fiocruz. São Paulo: Revista do Arquivo São Paulo, Ano VI, n. 10, 2020.

DELMAS, Bruno. Arquivos para quê? Tradução de Danielle Ardaillon. São Paulo: Instituto Fernando Henrique Cardoso (iFHC), 2010.

PREFEITURA Municipal de Campinas; GODOY, Heliton Leite. Diretrizes Curriculares da Educação Básica para o Ensino Fundamental - Anos Iniciais: Um processo contínuo de 


\section{artigos}

\section{Difusão em Arquivos e o centro de memória - Unicamp}

reflexão e ação. Campinas, SP, 2012.

LE GOFF, Jacques. Documento/Monumento. In: Enciclopédia Einaudi. Lisboa: Imprensa Nacional, v. 1, 1984.

LEITE, Eduardo. Dados sobre o coronavírus expõem fragilidade da preservação digital. O Estado de S. Paulo, São Paulo, 08 jun. 2020. Disponível em:

<https://brasil.estadao.com.br/blogs/edmundo-leite/dados-sobre-coronavirusexpoem-fragilidade-da-preservacao-digital/>. Acesso em: 05 ago. 2020.

LEITE, Eduardo. Difusão Acervo Estadão ou "Compartilhando joias de um tesouro". São Paulo: Revista do Arquivo São Paulo, Ano VI, n. 10, 2020.

PARRELA. Difusão do Arquivo - comunicação, mediação e ações educativas e culturais. São Paulo: Revista do Arquivo São Paulo, Ano VI, n. 10, 2020.

PEREIRA, Railane Antunes. Arquivos, Educação Patrimonial e Ensino de História: os benefícios e obstáculos dessas aproximações. Brasília: XXIX Simpósio Nacional de História - ANPUH, 2017. Disponível em:

<https://www.snh2017.anpuh.org/resources/anais/54/1490652935_ARQUIVO_Arquivo s, EducacaoPatrimonialeEnsinodeHistoria-

osbeneficioseobstaculosdessasaproximacoes..pdf> Acesso em: 15 jul. 2020.

PUT, Eddy. Uma flora dos arquivos? Pesquisa tipológica de fontes de arquivo da era moderna (séculos XVI-XVIII). São Paulo: Revista do Arquivo São Paulo, Ano VI, n. 10, 2020

ROCKEMBACH, Moisés. Difusão em arquivos: uma função arquivística, informacional e comunicacional. Rio de Janeiro: Informação Arquivística, v. 4, n. 1, 2015.

ROUSSEAU, Jean-Yves; COUTURE, Carol. Fundamentos da disciplina arquivística. Lisboa: Dom Quixote, 1998.

VAZ, Gláucia Aparecida; VENÂNCIO, Renato Pinto. Marketing, difusão, ação e mediação cultural em arquivos públicos. João Pessoa: RACIn, v. 6, n. 1, 2018. 